\title{
Generation of an EphA4 conditional allele in mice
}

\author{
Julia E. Herrmann ${ }^{1}$, Morgan A. Pence ${ }^{2}$, Emanuel A. Shapera ${ }^{1}$, Ravi R. Shah ${ }^{1}$, Cédric G. \\ Geoffroy ${ }^{1}$, and Binhai Zheng ${ }^{1,2,{ }^{*}}$ \\ 1 Department of Neurosciences, University of California San Diego, School of Medicine, 9500 \\ Gilman Drive, MC 0691, La Jolla, California 92093, USA \\ 2 Biomedical Sciences Graduate Program, University of California San Diego, School of \\ Medicine, 9500 Gilman Drive, MC 0691, La Jolla, California 92093, USA
}

\section{Summary}

Ephrins and Eph receptor tyrosine kinases are cell surface molecules that serve a multitude of functions in cell-cell communication in development, physiology and disease. EphA4 is a promiscuous member of the EphA subclass of Eph receptors and can bind to both EphrinAs and EphrinBs. In addition to its well-established roles in guiding the development of neuronal connectivity, EphA4 has been implicated for a role in synaptic plasticity, vascular formation, axon regeneration and central nervous system (CNS) repair following injury. However, the study of its role in the adult stage has been hampered by confounding developmental defects in EphA4 germline mutants. Here, we report the generation and molecular characterization of an EphA4 conditional allele along with a novel null allele with a knockin fluorescent reporter gene $(m C F P)$. The conditional allele will be useful in ascertaining post-developmental and/or cell type-specific function of EphA4 in physiology, injury and disease.

\section{Keywords}

EphA4; conditional allele; neural development; neural plasticity; cell-cell signaling

\begin{abstract}
Ephrins and their Eph receptors are best characterized for their roles in developmental axon guidance (Pasquale, 2008). Both the Ephrin ligands and the Eph receptors are divided into the $A$ and $B$ subclasses. In mammals, there are nine subclass A Eph (EphA) receptors that bind to five subclass A Ephrin (EphrinA) ligands, and five EphB receptors that bind to three EphrinB ligands. Crosstalk among ligands and receptors within a subclass is common, but a certain level of crosstalk also exists between subclasses. During neural development, Ephs and Ephrins are often expressed in a gradient fashion in neurons and/or their target tissues to guide the formation of topographic maps, which ensures the maintenance of the spatial order of neural information (Flanagan, 2006). In addition to their roles in axon guidance, Ephrins and Ephs have been implicated in variety of other biological processes both inside and outside of the nervous system, including dendritic spine morphology and synapse formation, synaptic function and plasticity, responses to a CNS injury, angiogenesis, immune function, tissue homeostasis and cancer (Goldshmit et al., 2006a; Goldshmit et al., 2006b; Klein,
\end{abstract} 2009; Kuijper et al., 2007; Lai and Ip, 2009; Murai et al., 2003; Pasquale, 2008).

Several features of Eph/Ephrin-mediated cell-cell signaling make it challenging to assess the roles of these molecules in vivo, particularly when an individual Ephrin or Eph is expressed

*Correspondence to: Binhai Zheng, Ph.D., Department of Neurosciences, University of California San Diego, 9500 Gilman Drive, MC 0691, La Jolla, CA 92093-0691, USA, Phone: (858) 534-5807, Fax: (858) 822-1021, binhai@ucsd.edu. 
by multiple cell types. In addition to the documented crosstalk within and between subclasses, Ephs and Ephrins can mediate bidirectional signaling where either Eph (in forward signaling) or Ephrin (in reverse signaling) can serve as the receptor (Egea and Klein, 2007). Eph/Ephrin-mediated signaling may lead to either repulsion or attraction. Ephs and Ephrins can interact in cis when they are co-expressed by the same cells, which may modulate their signaling in trans (between cells).

EphA4 is a member of the EphA subclass and can bind to both EphrinAs and EphrinBs. The promiscuous nature of its interaction with Ephrins makes EphA4 available to participate in a variety of cell-cell signaling events. EphA4 is expressed by multiple cell types during development, after injury, and in disease (Goldshmit et al., 2006a; Goldshmit et al., 2004; Oki et al., 2008; Pasquale, 2008; Ting et al., 2009). In addition to its roles in developmental axon guidance, it has been implicated for a role in synaptic plasticity, vascular formation, axon regeneration and CNS repair after injury (Goldshmit et al., 2006a; Goldshmit et al., 2004; Grunwald et al., 2004; Murai et al., 2003). Because of the complexities in Eph-Ephrin signaling, the precise role of EphA4 in a given cell type in these processes awaits further elucidation.

Such complexities are amply illustrated by the proposed role of EphA4 in axon regeneration and spinal cord repair following injury (Goldshmit et al., 2004). EphA4 is expressed by both damaged corticospinal tract axons and reactive astrocytes (Fabes et al., 2006; Goldshmit et al., 2004). It is not clear whether axonal or astroglial expression of EphA4 - or both underlies its proposed role in spinal cord repair. Furthermore, developmental expression of EphA4 by endothelial cells may lead to abnormalities in CNS vasculature, thereby indirectly influencing CNS repair in EphA4 germline mutants (Goldshmit et al., 2006a). Finally, the profound behavioral deficit of EphA4 germline mutants (a hindlimb hopping gait, which reflects developmental axon guidance defects) (Dottori et al., 1998; Kullander et al., 2003) precludes a conclusive analysis of behavioral recovery following spinal cord injury in these mice (our unpublished data). Thus, a conditional knockout system where EphA4 function is disrupted in a cell type-specific manner and/or after development is complete would be valuable in interrogating the function of EphA4 in CNS repair. Coupled with an inducible Cre mouse, this system would allow for the assessment of the temporal role of EphA4 following injury, which is directly relevant to the therapeutic time window for any treatment of spinal cord injury.

In order to establish an inducible and/or cell type-specific EphA4 gene deletion system in mice, we generated a conditional allele of EphA4. From one gene-targeting event along with Cre/FLP-mediated recombination, we generated an EphA4 conditional allele and a novel EphA4 null allele with a fluorescent reporter gene. The strategy for gene targeting and Cre/ FLP-mediated recombination is outlined in Figure 1a. The murine EphA4 gene has eighteen exons. We designed the targeting vector to flox (flank with loxP sites) the third exon so that following Cre-mediated excision of exon 3 splicing of exon 2 to exon 4 would lead to a frameshift in the downstream coding sequence, resulting in a null allele. Preceding the floxed exon 3, two Frt sites flank a reporter/selection cassette containing a splice acceptor $(S A)$ and an $m C F P$ reporter gene (encoding a membrane-targeted cyan fluorescent protein) (Godinho et al., 2005) in addition to a Neomycin resistance gene (Neo) so that a knockin reporter line labeling neuronal processes more than neuronal cell bodies would be generated from the same gene targeting event.

After electroporation of the targeting vector into mouse embryonic stem cells, targeted clones were detected by Southern blot analysis with a $3^{\prime}$ external probe and verified at the $5^{\prime}$ end with long range PCR analysis spanning the left arm of homology (Fig. 1b,c). Following germline transmission, the targeted allele could be genotyped by PCR using a primer pair 
flanking the 3' loxP site (Fig. 1d). The targeted allele was bred to an FLP deleter mouse (ACTB:FLPe) (Rodriguez et al., 2000) to excise the SA-mCFP-Neo cassette, giving rise to the desired conditional allele $\left(E p h A 4^{F l o x}\right)$ with a floxed exon 3 (Fig. 1a,e). In a separate mating, the targeted allele was bred to a Cre deleter mouse (EIIA-Cre) (Lakso et al., 1996; $\mathrm{Xu}$ et al., 2001) to excise the floxed exon 3, giving rise to a novel null allele $\left(\right.$ EphA4 ${ }^{m C F P N e o N u l l}$ ) with the knockin $m C F P$ reporter gene (Fig. 1a,f).

Homozygous EphA4 $4^{m C F N e o F l o x}$ mice exhibited a hopping gait (100\% penetrance, $\left.\mathrm{n}=6\right)$, a phenotype described previously for other EphA4 mutants that has been attributed to a defective central pattern generator (Dottori et al., 1998; Helmbacher et al., 2000; Kullander et al., 2003; Kullander et al., 2001; Leighton et al., 2001). This suggests that the EphA4 ${ }^{m C F P N e o F l o x}$ allele is a loss-of-function allele, as would be expected if exon 2 of EphA4 were spliced to the $S A-m C F P$ reporter gene in this allele.

Following FLP-mediated excision of the SA-mCFP-Neo cassette, the targeted allele was converted to the conditional allele $\left(E p h A 4^{F l o x}\right)$ that would be expected to differ from the wild type allele only by short sequences at the two loxP insertion sites (Fig. 1a).

Homozygous EphA4 ${ }^{\text {Flox }}$ mice were obtained at a Mendelian ratio from intercrosses between heterozygotes. They were viable, fertile and morphologically indistinguishable from their wild type or heterozygous littermates. Sequence analysis of genomic DNA from homozygous EphA4 Flox mice confirmed the presence of the two loxP sites (in addition to a single Frt site associated with the $5^{\prime} \operatorname{lox} P$ site) at the expected locations (data not shown). Because these two loxP sites have been demonstrated to be functional in the targeted allele (EphA4 $\left.{ }^{m C F P N e o F l o x}\right)$, they are expected to be functional as substrates for Cre recombination in the conditional allele $\left(E p h A 4^{F l o x}\right)$.

Importantly, homozygous EphA4 Flox mice exhibited a normal gait (n > 20), indicating that, as expected, FLP-mediated deletion of the $S A-m C F P$-Neo cassette reversed the behavioral abnormality associated with the targeted allele. Western blot analysis on total brain extracts from homozygous EphA4 ${ }^{\text {Flox }}$ mice detected a level of EphA4 expression not significantly different from that of wild type littermates (Fig. 2a,b). To determine whether the expression pattern of EphA4 is altered in homozygous EphA4 ${ }^{\text {Flox }}$ mice, we performed

immunohistochemistry on adult brain tissue sections. In the wild type adult mouse brain, EphA4 is strongly expressed in the process-rich layers of the hippocampus (Fig. 3a, a'), as described previously (Liebl et al., 2003; Martone et al., 1997; Murai et al., 2003). EphA4 is expressed in a similar pattern in homozygous EphA4 Flox mice (Fig. 3b, b'). Taken together, these results indicate that EphA4 expression is not disrupted in the conditional mutants in the absence of a Cre transgene.

Following Cre-mediated excision of exon 3, the targeted allele was converted to the EphA4 ${ }^{m C F P N e o N u l l}$ allele, which was expected to be a null (Fig. 1a). Indeed, homozygous EphA4 ${ }^{m C F P N e o N u l l}$ mice exhibited the hindlimb hopping gait $(100 \%$ penetrance, $\mathrm{n}=12)$. Western blot analysis on total brain extracts confirmed the absence of EphA4 protein in homozygous EphA4 ${ }^{m C F P N e o N u l l}$ mutants (Fig. 2c). This result was confirmed with immunohistochemistry on adult brain tissues, where EphA4 immunoreactivity was at background levels in homozygous EphA4 ${ }^{m C F P N e o N u l l}$ mice (Fig. 3c, $\mathrm{c}^{\prime}$ ). Together, these results establish the EphA4mCFPNeoNull allele as a null allele.

To determine if the $m C F P$ reporter gene is functional in EphA4 $4^{m C F P N e o N u l l}$ mice, we stained adult mouse brain sections with antibodies to green fluorescent protein (GFP), which recognize mCFP. With immunohistochemistry, we confirmed mCFP expression in the hippocampus of mice heterozygous for the EphA4 ${ }^{m C F P N e o N u l l}$ allele (Fig. 3d-e'). The pattern of mCFP immunostaining in the hippocampus of the knockin mice resembles that of 
EphA4 in wild type mice in that the process-rich layers of the CA3 area are strongly immunoreactive. This result suggests that $\mathrm{mCFP}$ is distributed to neuronal processes as would be expected for a membrane-targeted reporter gene product (Godinho et al., 2005). We did not detect significant amount of mCFP by direct fluorescence on fixed adult brain tissue sections (data not shown). There is a detectable level of mCFP by direct fluorescence on fresh frozen adult brain tissue sections (data not shown), but this level is so low that it is unlikely to be useful for applications such as in vivo imaging.

In summary, we generated a conditional allele for the EphA4 gene that does not disrupt EphA4 expression prior to Cre-mediated excision of the floxed exon. Along this process, we also generated a novel EphA4 null allele marked with a knockin $m C F P$ reporter gene. The EphA4 ${ }^{F l o x}$ conditional allele will be useful in analyzing the role of EphA4 in specific cell types when crossed to cell type-specific Cre mouse lines. In addition, this allele can be crossed to inducible Cre mouse lines to examine the role of EphA4 in a range of biological processes without confounding developmental defects in EphA4 germline mutants and to investigate the temporal role of EphA4 in physiology, injury and disease.

\section{MATERIALS AND METHODS}

\section{Gene targeting and molecular characterization}

A replacement gene targeting vector was constructed with a $3.7 \mathrm{~kb}$ left arm of homology, an Frt-flanked $S A-m C F P$-Neo reporter gene and positive selection cassette, a loxP site, a $1.7 \mathrm{~kb}$ middle arm of homology, a second loxP site (in the same orientation as the first one), a 3.8 $\mathrm{kb}$ right arm of homology, and a $T K$ (Herpes Simplex Virus Thymidine Kinase gene) negative selection marker. The homology arms were amplified from isogenic 129S5 genomic DNA with a high fidelity PCR amplification kit (Roche) and sequence verified. The second ( $\left.3^{\prime}\right)$ loxP site is marked with an EcoRI site so that the conditionally targeted allele (resulting from a crossover in the left arm and a crossover in the right arm, see Fig. 1a) can be distinguished from the non-conditional allele (resulting from a crossover in the left arm and a cross over in the middle arm) as well as the wild type allele on a Southern blot with EcoRI digested genomic DNA hybridized with the 3' external probe: wild type, 11.5 $\mathrm{kb}$; conditionally targeted allele, $4.9 \mathrm{~kb}$ (Fig. 1b); non-conditionally targeted allele, $6.8 \mathrm{~kb}$ (data not shown). Gene targeting was performed in AB2.2 mouse embryonic stem cells as described (Ramirez-Solis et al., 1993). We observed a $\sim 12 \%$ targeting frequency for the conditionally targeted allele and a $\sim 11 \%$ targeting frequency for the non-conditionally targeted allele. The conditionally targeted allele is simply referred to as the targeted allele here, and the non-conditionally targeted allele was not pursued further. The targeted allele $\left(\right.$ EphA4 $\left.4^{m C F N e o F l o x}\right)$ was transmitted though the germline following blastocyst injection and breeding of chimera mice to C57BL/6 females. Sequences of primers used for constructing the homology arms and for genotyping will be provided upon request.

\section{Immunohistochemistry}

Two to four month old mice were euthanized with anesthetic overdose and perfused transcardially with $4 \%$ paraformaldehyde. Brains were extracted and post fixed in paraformaldehyde for 30 minutes followed by cryoprotection in $30 \%$ sucrose for 48 hours, embedded in OCT, frozen, and cut into $40 \mu \mathrm{m}$ cryosections and maintained in $0.05 \%$ azide solution at $4^{\circ} \mathrm{C}$. Tissue sections were stained immunohistochemically using antibodies to EphA4 (rabbit, 1:500; Upstate) and GFP (rabbit, 1:500; Invitrogen) after blocking for one hour in 5\% normal goat serum in a high salt buffer (Lee et al., 2007). Sections were incubated in primary antibodies at $4^{\circ}$ Covernight. Secondary antibodies included Cy3 antirabbit (Jackson) or Alexa Fluor 488 anti-rabbit (Invitrogen). Images were acquired using a 
Zeiss Axio Imager M1 microscope with an AxioCam MRm monochrome camera and pseudocolored.

\section{Western blot}

Proteins were made from the brains of 2-4 month old mice, and concentrations determined by the Lowry protein assay (Bio-Rad DC Protein Assay kit). $15 \mu \mathrm{g}$ of protein per sample was separated using SDS-PAGE with a 10\% resolving gel and transferred onto a nitrocellulose membrane (Amersham Biosciences). Primary antibodies (rabbit anti-EphA4 at $1: 100$, Santa Cruz; mouse anti- $\alpha$-Tubulin at 1:1000, Sigma) were incubated overnight at $4{ }^{\circ} \mathrm{C}$, followed by HRP-conjugated secondary antibodies (Pierce), and detected using Supersignal West Dura ECL solution (Pierce). Images were captured using a Syngene GeneGnome chemiluminescence detection system and quantified using Syngene GeneTools analysis software.

\section{Acknowledgments}

We thank Rachel Wong for the $m C F P$ plasmid; Susan Dymecki for the ACTB:FLPe transgenic line; Claire Clelland and Wendy Huang for their contribution in the initial steps of constructing the targeting vector; Andrea Chan and Yuhong Zhu for technical assistance. Blastocyst injection was performed by the UCSD Transgenic Mouse Core. This work is supported by grants from the Roman Reed Spinal Cord Injury Research Fund of California and NIH/ NINDS (R01NS054734). J.E.H. was supported by a Christopher and Dana Reeve Foundation Postdoctoral Fellowship.

\section{References}

Dottori M, Hartley L, Galea M, Paxinos G, Polizzotto M, Kilpatrick T, Bartlett PF, Murphy M, Kontgen F, Boyd AW. EphA4 (Sek1) receptor tyrosine kinase is required for the development of the corticospinal tract. Proc Natl Acad Sci U S A. 1998; 95:13248-13253. [PubMed: 9789074]

Egea J, Klein R. Bidirectional Eph-ephrin signaling during axon guidance. Trends Cell Biol. 2007; 17:230-238. [PubMed: 17420126]

Fabes J, Anderson P, Yanez-Munoz RJ, Thrasher A, Brennan C, Bolsover S. Accumulation of the inhibitory receptor EphA4 may prevent regeneration of corticospinal tract axons following lesion. Eur J Neurosci. 2006; 23:1721-1730. [PubMed: 16623828]

Flanagan JG. Neural map specification by gradients. Curr Opin Neurobiol. 2006; 16:59-66. [PubMed: 16417998]

Godinho L, Mumm JS, Williams PR, Schroeter EH, Koerber A, Park SW, Leach SD, Wong RO. Targeting of amacrine cell neurites to appropriate synaptic laminae in the developing zebrafish retina. Development. 2005; 132:5069-5079. [PubMed: 16258076]

Goldshmit Y, Galea MP, Bartlett PF, Turnley AM. EphA4 regulates central nervous system vascular formation. J Comp Neurol. 2006a; 497:864-875. [PubMed: 16802330]

Goldshmit Y, Galea MP, Wise G, Bartlett PF, Turnley AM. Axonal regeneration and lack of astrocytic gliosis in EphA4-deficient mice. J Neurosci. 2004; 24:10064-10073. [PubMed: 15537875]

Goldshmit Y, McLenachan S, Turnley A. Roles of Eph receptors and ephrins in the normal and damaged adult CNS. Brain Res Rev. 2006b; 52:327-345. [PubMed: 16774788]

Grunwald IC, Korte M, Adelmann G, Plueck A, Kullander K, Adams RH, Frotscher M, Bonhoeffer T, Klein R. Hippocampal plasticity requires postsynaptic ephrinBs. Nat Neurosci. 2004; 7:33-40. [PubMed: 14699416]

Helmbacher F, Schneider-Maunoury S, Topilko P, Tiret L, Charnay P. Targeting of the EphA4 tyrosine kinase receptor affects dorsal/ventral pathfinding of limb motor axons. Development. 2000; 127:3313-3324. [PubMed: 10887087]

Klein R. Bidirectional modulation of synaptic functions by Eph/ephrin signaling. Nat Neurosci. 2009; 12:15-20. [PubMed: 19029886]

Kuijper S, Turner CJ, Adams RH. Regulation of angiogenesis by Eph-ephrin interactions. Trends Cardiovasc Med. 2007; 17:145-151. [PubMed: 17574121] 
Kullander K, Butt SJ, Lebret JM, Lundfald L, Restrepo CE, Rydstrom A, Klein R, Kiehn O. Role of EphA4 and EphrinB3 in local neuronal circuits that control walking. Science. 2003; 299:18891892. [PubMed: 12649481]

Kullander K, Mather NK, Diella F, Dottori M, Boyd AW, Klein R. Kinase-dependent and kinaseindependent functions of EphA4 receptors in major axon tract formation in vivo. Neuron. 2001; 29:73-84. [PubMed: 11182082]

Lai KO, Ip NY. Synapse development and plasticity: roles of ephrin/Eph receptor signaling. Curr Opin Neurobiol. 2009

Lakso M, Pichel JG, Gorman JR, Sauer B, Okamoto Y, Lee E, Alt FW, Westphal H. Efficient in vivo manipulation of mouse genomic sequences at the zygote stage. Proc Natl Acad Sci U S A. 1996; 93:5860-5865. [PubMed: 8650183]

Lee JK, Johnson CS, Wrathall JR. Up-regulation of 5-HT2 receptors is involved in the increased Hreflex amplitude after contusive spinal cord injury. Exp Neurol. 2007; 203:502-511. [PubMed: 17059818]

Leighton PA, Mitchell KJ, Goodrich LV, Lu X, Pinson K, Scherz P, Skarnes WC, Tessier-Lavigne M. Defining brain wiring patterns and mechanisms through gene trapping in mice. Nature. 2001; 410:174-179. [PubMed: 11242070]

Liebl DJ, Morris CJ, Henkemeyer M, Parada LF. mRNA expression of ephrins and Eph receptor tyrosine kinases in the neonatal and adult mouse central nervous system. J Neurosci Res. 2003; 71:7-22. [PubMed: 12478610]

Martone ME, Holash JA, Bayardo A, Pasquale EB, Ellisman MH. Immunolocalization of the receptor tyrosine kinase EphA4 in the adult rat central nervous system. Brain Res. 1997; 771:238-250. [PubMed: 9401744]

Murai KK, Nguyen LN, Irie F, Yamaguchi Y, Pasquale EB. Control of hippocampal dendritic spine morphology through ephrin-A3/EphA4 signaling. Nat Neurosci. 2003; 6:153-160. [PubMed: 12496762]

Oki M, Yamamoto H, Taniguchi H, Adachi Y, Imai K, Shinomura Y. Overexpression of the receptor tyrosine kinase EphA4 in human gastric cancers. World J Gastroenterol. 2008; 14:5650-5656. [PubMed: 18837080]

Pasquale EB. Eph-ephrin bidirectional signaling in physiology and disease. Cell. 2008; 133:38-52. [PubMed: 18394988]

Ramirez-Solis R, Davis AC, Bradley A. Gene targeting in embryonic stem cells. Methods Enzymol. 1993; 225:855-878. [PubMed: 8231891]

Rodriguez CI, Buchholz F, Galloway J, Sequerra R, Kasper J, Ayala R, Stewart AF, Dymecki SM. High-efficiency deleter mice show that FLPe is an alternative to Cre-loxP. Nat Genet. 2000; 25:139-140. [PubMed: 10835623]

Ting MC, Wu NL, Roybal PG, Sun J, Liu L, Yen Y, Maxson RE Jr. EphA4 as an effector of Twist1 in the guidance of osteogenic precursor cells during calvarial bone growth and in craniosynostosis. Development. 2009; 136:855-864. [PubMed: 19201948]

Xu X, Li C, Garrett-Beal L, Larson D, Wynshaw-Boris A, Deng CX. Direct removal in the mouse of a floxed neo gene from a three-loxP conditional knockout allele by two novel approaches. Genesis. 2001; 30:1-6. [PubMed: 11353511] 


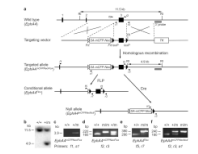

Fig. 1.

Gene targeting and FLP/Cre-mediated recombination at the EphA4 locus. (a) The scheme for gene targeting and Cre/FLP-mediated recombination. Only the first three (black vertical bars) of 18 total exons are shown for simplicity. RI, EcoRI; $S A$, splice acceptor; $m C F P$, coding sequence for a membrane-targeted cyan fluorescent protein; Neo, neomycin resistance gene; $T K$, herpes simplex virus thymidine kinase gene; open triangle, Frt site; black triangle, loxP site. Small arrowheads indicate primers used in PCRs to confirm gene targeting or Cre/FLP-mediated recombination, or for genotyping. (b) Representative Southern blot to detect targeted clones with the $3^{\prime}$ external probe. + , wild type allele; $\mathrm{m}$, mutant allele. (c) Long range PCR analysis to verify correct homologous recombination at the left arm of homology. Primers $f l$ and $s l$ are located just outside of the left arm of homology in the targeted allele (a). (d) PCR analysis to genotype the EphA4 ${ }^{\text {mCFPNeoFlox }}$ allele. This PCR can also be used to genotype the EphA4Flox allele (not shown). (e) PCR analysis to confirm the deletion of the $S A-m C F P$-Neo cassette in homozygous EphA4Flox mice. (f) PCR analysis to genotype EphA4 ${ }^{m C F P N e o N u l l}$ mice. 


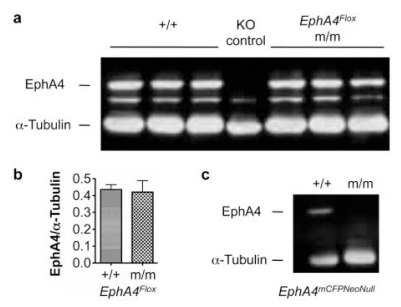

Fig. 2.

Western blot analyses on adult brain extracts of EphA4 mutants. (a) Western blot analysis on brain extracts showing similar levels of EphA4 expression between wild type control $(+/+)$ mice and mice homozygous for the conditional allele $\left(E p h A 4^{F l o x} \mathrm{~m} / \mathrm{m}\right)$. Each lane represents a different mouse. The knockout (KO) control used is an EphA4 gene trap mutant (Leighton et al., 2001). There is a non-specific band just below the band for EphA4. (b) Quantification of results in (a). There is no statistically significant difference between homozygous EphA4 $4^{\text {Flox }}$ mice and wild type littermates (Student's $t$-test). (c) Western blot analysis on total brain extract to confirm the absence of EphA4 protein expression in a representative

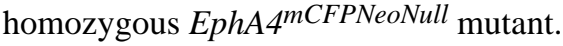



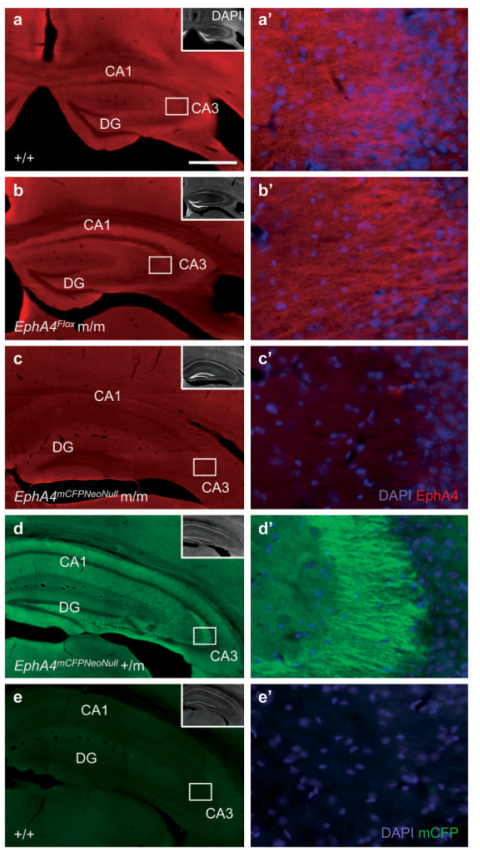

Fig. 3.

EphA4 or mCFP immunostaining of hippocampal regions from adult wild type and EphA4 mutant mice. (a-e) Lower magnification views of hippocampal regions immunostained with EphA4 $(a-c)$ or mCFP $(d, e)$. The genotypes are indicated in the lower left corner of each panel. DG, dentate gyrus. Small insets, corresponding DAPI nuclear staining. $\left(\mathbf{a}^{\prime}-\mathbf{e}^{\prime}\right)$ Higher magnification views of the corresponding boxed areas in $(\mathrm{a}-\mathrm{e})$ to show EphA4 $\left(\mathrm{a}^{\prime}-\mathrm{c}^{\prime}\right)$ or $\operatorname{mCFP}\left(\mathrm{d}^{\prime}, \mathrm{e}^{\prime}\right)$ immunoreactivity in the process-rich areas of CA3. Note that EphA4 was detected in wild type $(+/+)$ and the conditional mutant $\left(E p h A 4^{F l o x} \mathrm{~m} / \mathrm{m}\right)$ but not in the null mutant $\left(E p h A 4^{m C F P N e o N u l l} \mathrm{~m} / \mathrm{m}\right)$, while $\mathrm{mCFP}$ was detected in the heterozygous knockin null mutant $\left(\right.$ EphA4 $\left.4^{m C F P N e o N u l l}+/ \mathrm{m}\right)$ but not in the wild type $(+/+)$ mouse. Red = EphA4; Blue $=$ DAPI; Green $=$ mCFP. Scale bar $=500 \mu \mathrm{m}(\mathrm{a}-\mathrm{e}), 50 \mu \mathrm{m}\left(\mathrm{a}^{\prime}-\mathrm{e}^{\prime}\right)$. 